\title{
Metabolic Changes in Larvae of Predator Chrysopa sinica Fed on Azadirachtin-Treated Plutella xylostella Larvae
}

\author{
Peiwen Zhang ${ }^{1,2}$, You Zhou ${ }^{3}\left(\mathbb{D}\right.$, Deqiang Qin ${ }^{1}$, Jianjun Chen ${ }^{2, *}$ and Zhixiang Zhang ${ }^{1, *(D)}$ \\ 1 Key Laboratory of Natural Pesticide and Chemical Biology, Ministry of Education, South China Agricultural \\ University, Guangzhou 510642, China; peiwen.zhang@ufl.edu (P.Z.); 20181023002@stu.scau.edu.cn (D.Q.) \\ 2 Mid-Florida Research and Education Center, Department of Environmental Horticulture, Institute of Food \\ and Agricultural Sciences, University of Florida, Apopka, FL 32703, USA \\ 3 College of Biology and Food Engineering, Chongqing Three Gorges University, Chongqing 404100, China; \\ youzhou@sanxiau.edu.cn \\ * Correspondence: jjchen@ufl.edu (J.C.); zdsys@scau.edu.cn (Z.Z.)
}

check for

updates

Citation: Zhang, P.; Zhou, Y.; Qin, D.;

Chen, J.; Zhang, Z. Metabolic

Changes in Larvae of Predator

Chrysopa sinica Fed on

Azadirachtin-Treated Plutella

xylostella Larvae. Metabolites 2022, 12,

158. https://doi.org/10.3390/

metabo12020158

Academic Editor:

Hirokazu Kawagishi

Received: 5 January 2022

Accepted: 5 February 2022

Published: 8 February 2022

Publisher's Note: MDPI stays neutral with regard to jurisdictional claims in published maps and institutional affiliations.

Copyright: (c) 2022 by the authors. Licensee MDPI, Basel, Switzerland. This article is an open access article distributed under the terms and conditions of the Creative Commons Attribution (CC BY) license (https:// creativecommons.org/licenses/by/ $4.0 /)$.

\begin{abstract}
Biological control is a key component of integrated pest management (IPM). To suppress pests in a certain threshold, chemical control is used in combination with biological and other control methods. An essential premise for using pesticides in IPM is to ascertain their compatibility with beneficial insects. Chrysopa sinica (Neuroptera: Chrysopidae) is an important predator of various pests and used for pest management. This study was intended to analyze metabolic changes in C. sinica larvae after feeding on azadirachtin-treated Plutella xylostella (Lepidoptera, Plutellidae) larvae through a non-targeted LC-MS (Liquid chromatography-mass spectrometry) based metabolomics analysis. Results showed that $C$. sinica larvae did not die after consuming $P$. xylostella larvae treated with azadirachtin. However, their pupation and eclosion were adversely affected, resulting in an impairment in the completion of their life cycle. Feeding $C$. sinica larvae with azadirachtin-treated P. xylostella larvae affected over 10,000 metabolites across more than 20 pathways, including the metabolism of amino acids, carbohydrates, lipid, cofactors, and vitamins in C. sinica larvae, of which changes in amnio acid metabolism were particularly pronounced. A working model was proposed to illustrate differential changes in 20 metabolites related to some amino acid metabolisms. Among them, 15 were markedly reduced and only five were elevated. Our results suggest that azadirachtin application may not be exclusively compatible with the use of the predator $C$. sinica for control of P. xylostella. It is recommended that the compatibility should be evaluated not only based on the survival of the predatory insects but also by the metabolic changes and the resultant detrimental effects on their development.
\end{abstract}

Keywords: azadirachtin; biological control; Chrysopa sinica; metabolomics; Plutella xylostella

\section{Introduction}

Integrated pest management (IPM) is a coordinated process using multiple methods, such as biological, chemical, cultural, mechanical, physical, and pest resistant or tolerant varieties for optimizing control of pests in an ecologically and economically sound manner [1]. Among them, chemical control and biological control are two common methods used either separately or in combination for managing insect pests during crop production. However, the use of pesticides may have adverse effects on non-target organisms, including predatory insects [2]. In order to minimize these problems and maintain sustainable control of insect pests, botanical pesticides are considered to be attractive alternatives for pest management. Compared with traditional synthetic insecticides, botanical pesticides have better eco-toxicological properties, including low toxicity, rapid degradation, and little impact on the environment, which makes them a suitable choice for pest control $[3,4]$.

Azadirachtin is the main active ingredient in neem (Azadirachta indica), which shows insecticidal, fungicidal, and bactericidal activities [3,5]. Azadirachtin as an insecticidal 
ingredient has been reported to effectively control more than 400 species of insects [6]. This compound displays multiple effects on insects and can be used as an insect repellent, antifeedant, growth retardant, molting inhibitor, and oviposition deterrent [5-7]. Azadirachtin was reported to be selective and would not affect important natural enemies of pests [8]. The application of azadirachtin did not affect the natural enemies of red spider mite, Mallada desjardinsi and Oligota pygmaea [9]. However, the neem oil cause anomalies on wings and legs of the non-target predator Podisus nigrispinus, thereby affecting its growth and causing its death [5]. Azadirachtin significantly affected longevity, number of attacked hosts, and progeny size of females on Opius concolor and could slightly reduce the survival rate of emerged Podisus maculiventris adults [10,11]. Additionally, azadirachtin was reported to affect searching time, mating behavior, and egg-laying rate of coconut mite predator $\mathrm{Neo}$ seiulus baraki [12]. Thus, even when botanical pesticides, such as azadirachtin are used in IPM, knowledge about their relative toxicity to and compatibility with predatory insects should be acquired.

The green lacewing, Chrysopa sinica Tiedet (Neuroptera: Chrysopidae), is a polyphagous natural enemy attacking several pests on various crops. The lacewing larvae prey on the insect's eggs, nymphs, larvae, and adults, such as nymphs and adults of Hemiptera, eggs and larvae of Lepidoptera [13-15]. They consume pollen, nectar, insect eggs, and younger larvae during its adult stage [14]. Lacewing is commercially produced in many countries for use as a biological agent against a wide range of pests, particularly in China [16]. Thus far, little information is available about azadirachtin effects on $C$. sinica although its effects on other lacewings were reported. There were no obvious effects on lacewing Chrysoperla carnea larvae after they were fed azadirachtin treated Sitotroga cerealella eggs [10,11]. Azadirachtin was not significantly toxic to eggs and pupae of $C$. carnea but caused a slight reduction in the number of pupae and adults [17]. However, other reports indicated that neem oil products adversely affect growth and development of lacewings Ceraeochrysa claveri either directly or indirectly [18-21]. To appropriately use azadirachtin and C. sinica for pest management, it is important to understand their compatibility not only based on the survival but also by their biochemical and metabolic responses.

Azadirachtin can adversely affect the endocrine system [22], cell division, protein synthesis [23], and different enzymes including NADPH cytochrome reductase, and cholinesterase [24,25]. Azadirachtin was reported to affect genes involved in larval or pupal development, defense responses, carbohydrate metabolism, signal transduction, and chemosensory behavior, as well as proteins implicated in energy metabolism, cytoskeletal structure, transcription and translation, and hormonal regulation in Drosophila larvae [26,27]. Similar effects were reported in Plodia interpunctella [28], Glyphodes pyloalis larvae [29], Ostrinia furnacalis larvae [30], Hyphantria cunea larvae [31], and Helicoverpa armigera [32]. Metabolomics is an important analytical tool of systems biology, which can identify all detectable metabolites in a biological system [33]. It is used to reveal endogenous metabolite changes that are caused by drug toxicity, disease process, or gene function [34-37]. Liquid chromatographic and gas chromatography-mass spectrometry (LC-MS and GC-MS) has been increasingly used to document metabolomic profiles of insect pests [24,38-41]. Recently, metabolic changes of Bactrocera dorsalis larvae [24] and Helicoverpa armigera [32] resulting from the treatment of azadirachtin have been reported, which provide more detailed information on azadirachtin actions to respective insect pests. Thus far, there has no metabolomic analysis of azadirachtin effects on $C$. sinica, especially after consumption of azadirachtin-treated preys.

The objectives of this study were to analyze metabolic changes in $C$. sinica larvae after feeding Plutella xylostella (Lepidoptera, Plutellidae) larvae treated with azadirachtin using ultra high performance liquid chromatograph coupled with tandem mass spectrometry (UHPLC-MS/MS), identify main metabolic pathways altered by the consumption of azadirachtin-treated prey, outline key components underlying the detrimental effects, and address likely problems for the use of azadirachtin and C. sinica in control of P. xylostella in crop production. 


\section{Results}

\subsection{Azadirachtin Activities against C. sinica}

The larvae of $C$. sinica fed with $P$. xylostella larvae that consumed azadirachtin-treated leaves $(\mathrm{T})$ showed no significant growth differences compared to those fed $P$. xylostella control (CK) as there were no larval mortalities between $\mathrm{T}$ and $\mathrm{CK}$ before pupation (data not shown). After stopping preying, mature larvae began to pupate. The head and tail of the larvae gradually curled together, and the tail drew silk to make cocoons (Figure 1(c-4)). However, there were $18 \%$ of the larvae in the $\mathrm{T}$ treatment that could not curl up and could not draw silk to make a cocoon (Figure 1(c-1-c-3)). When touching the larvae with a small brush, they still twisted but died in a few days. After 20 to 30 days, the $C$. sinica adults emerged from the pupae. In the $\mathrm{T}$ treatment, $24 \%$ of adults were deformed as they were unable to extend their wings and/or had malformed abdomen (Figure 1(d-1)), which were regarded as the failure to eclosion. Adults with fully extended wings and no growth defects were considered as successful eclosion (Figure 1(d-2,d-3)). Thus, the pupation and eclosion of $C$. sinica larvae were significantly affected by $T$ treatment. As shown in Figure 2, the proportion of larvae undergoing pupation from T treatment was significantly lower at $82.00 \pm 3.06 \%$ comparted to $100.00 \%$ in the CK $(p<0.01)$, and their eclosion was $76.00 \pm 1.15 \%$ in the $\mathrm{T}$ treatment against $98.00 \pm 1.48 \%$ of $\mathrm{CK}(p<0.001)$.
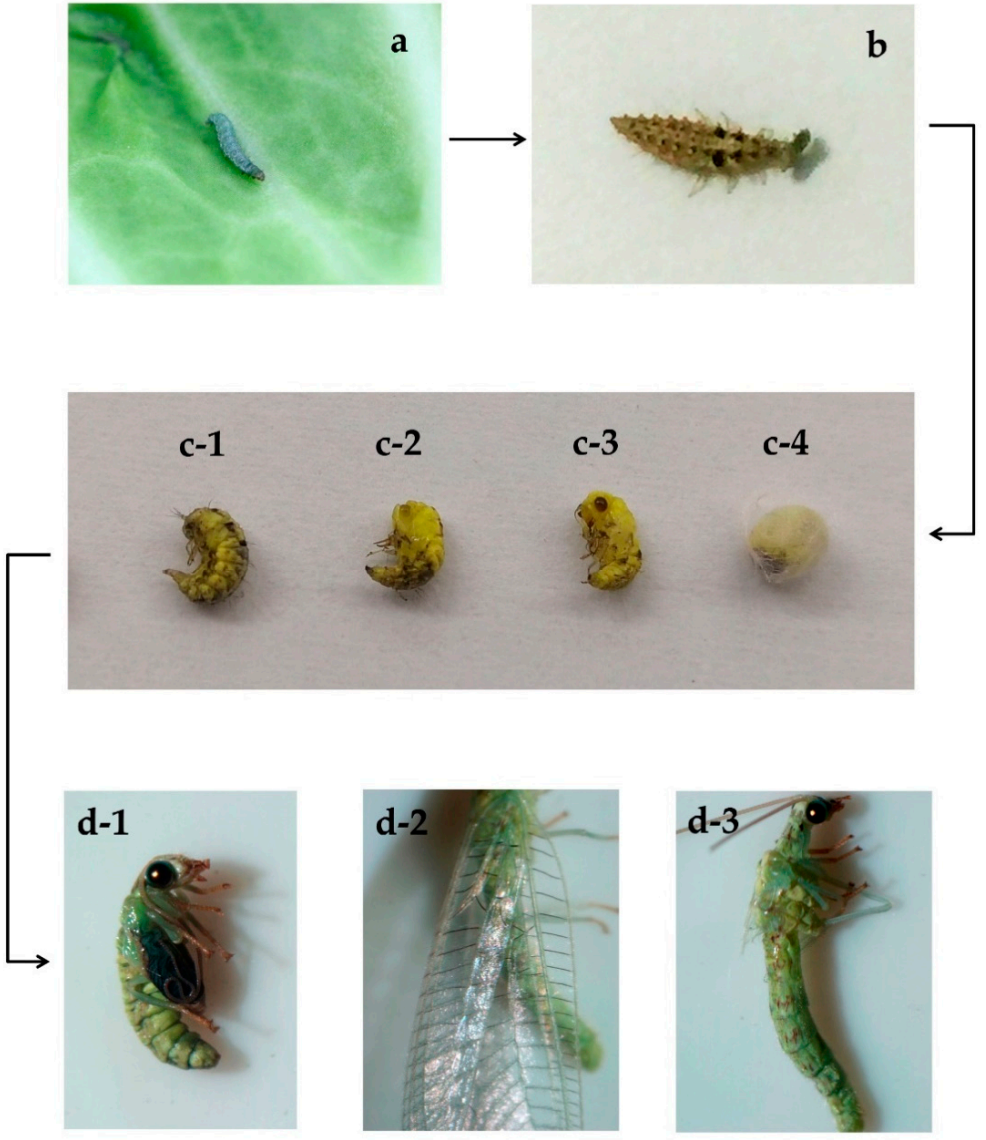

Figure 1. The process of monitoring P. xylostella larvae feeding on cabbage leaves and C. sinica larvae ingesting azadirachtin-treated $P$. xylostella larvae and subsequently their pupation and eclosion. A larva feeding on a cabbage leaf treated with azadirachtin (a). A C. sinica larva ingesting a P. xylostella larva (b). C. sinica larvae underwent pupation from curling to the formation of cocoon (c-1-c-4). The emergence of $C$. sinica adult: a deformed adult (d-1), normal adult (d-2), and normal adult after removing wings to show normal abdomen (d-3). 

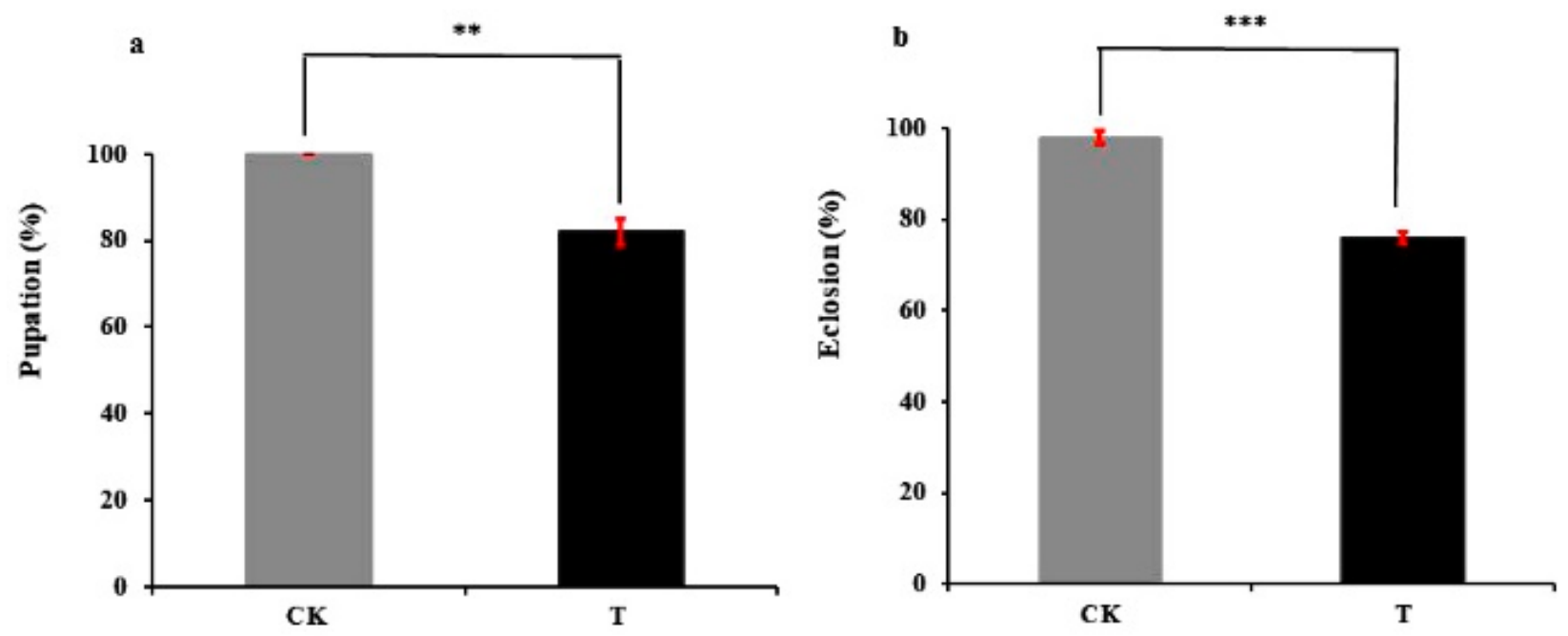

Figure 2. The proportion of mature $C$. sinica larvae underwent pupation (a) and eclosion (b) after ingesting azadirachtin-treated P. xylostella larvae. Data were expressed as the mean \pm S.E. and ${ }^{* *}$ and *** indicate significant differences at $p<0.01$ and $p<0.001$ levels based on Tukey's HSD test.

\subsection{Metabolic Profiles Analyzed by LC-MS}

The unsupervised PCA was used to check the quality of the data from the LC-MS analyses. In ESI+ mode, the PC1 and PC2 explained $30.9 \%$ and $11.4 \%$ of the total variance of all samples. In ESI- mode, the PC1 and PC2 explained $33.9 \%$ and $10.3 \%$ of the total variance. The supervised PLS-DA was performed to identify the metabolites responsible for the separation between CK and azadirachtin treatments (T). Results showed that in the ESI+ mode, the $R^{2} X, R^{2} Y, Q^{2} Y$, and RMSEE values in the PLS-DA model were 0.59, $0.753,0.369$, and 0.269 (Figure 3a), respectively; in the ESI- mode, the $R^{2} X, R^{2} Y, Q^{2} Y$, and RMSEE values in the PLS-DA model were $0.728,0.74,0.536$, and 0.276 (Figure 3b), respectively. Based on the OPLS-DA model, the $R^{2} X, R^{2} Y, Q^{2} Y$, and RMSEE values in the ESI+ mode were $0.59,0.753,0.337$, and 0.269 (Figure $4 a$ ), respectively. In the ESI- mode, the $R^{2} X, R^{2} Y, Q^{2} Y$, and RMSEE values in the ESI- mode were $0.728,0.74,0.512$ and 0.276 (Figure $4 b$ ), respectively.
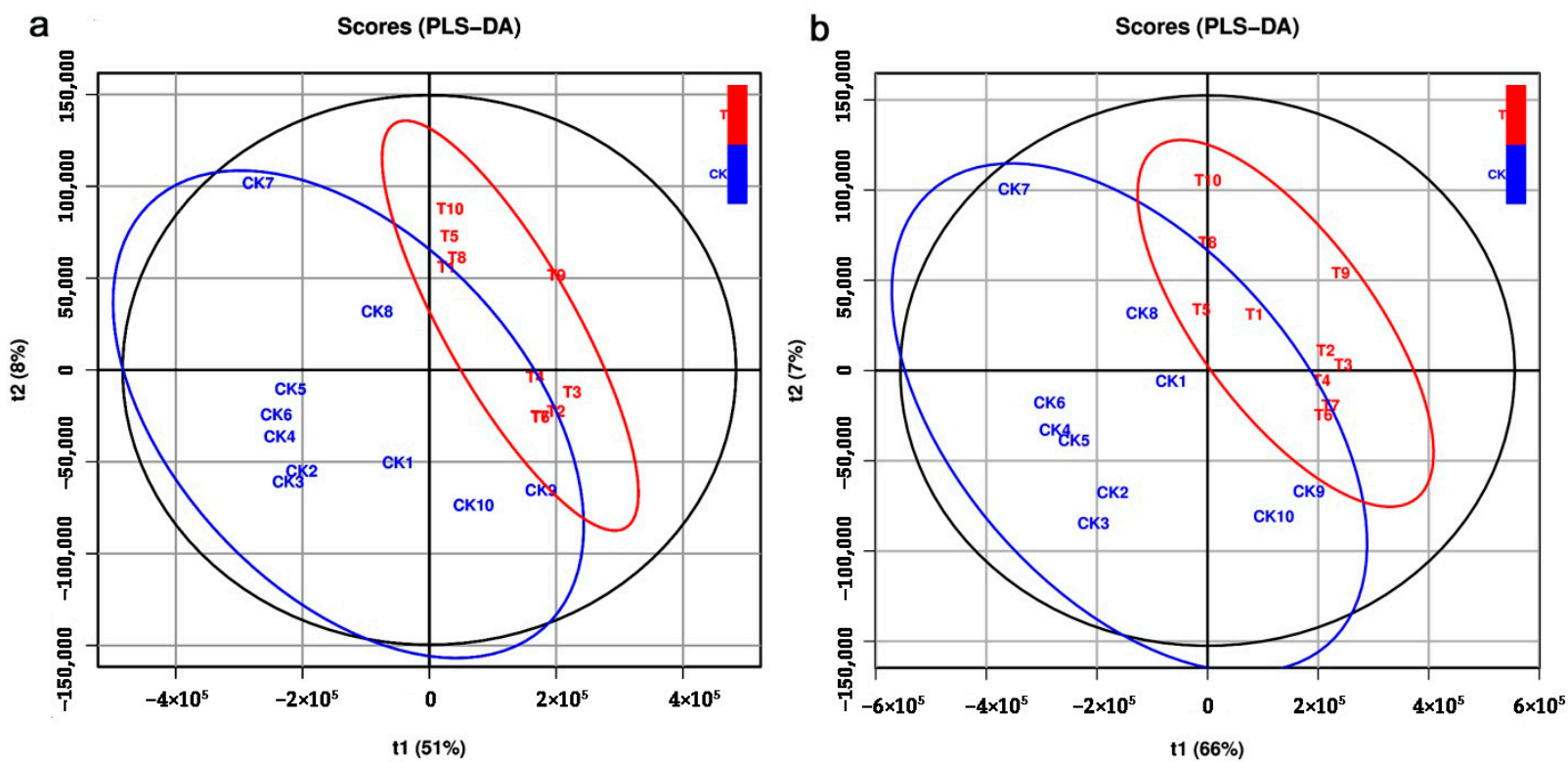

Figure 3. PLS-DA (partial least squares discriminant analysis) score plots derived from (a) positive ion mode (ESI+) and (b) negative ion mode (ESI-) in LC-MS metabolite profiles of C. sinica larvae. 
a

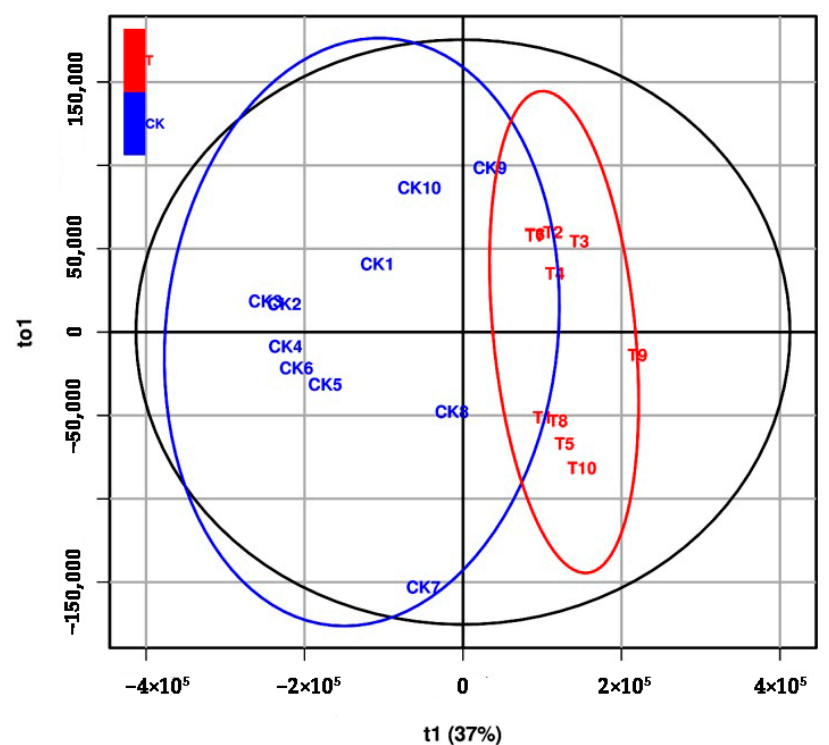

b

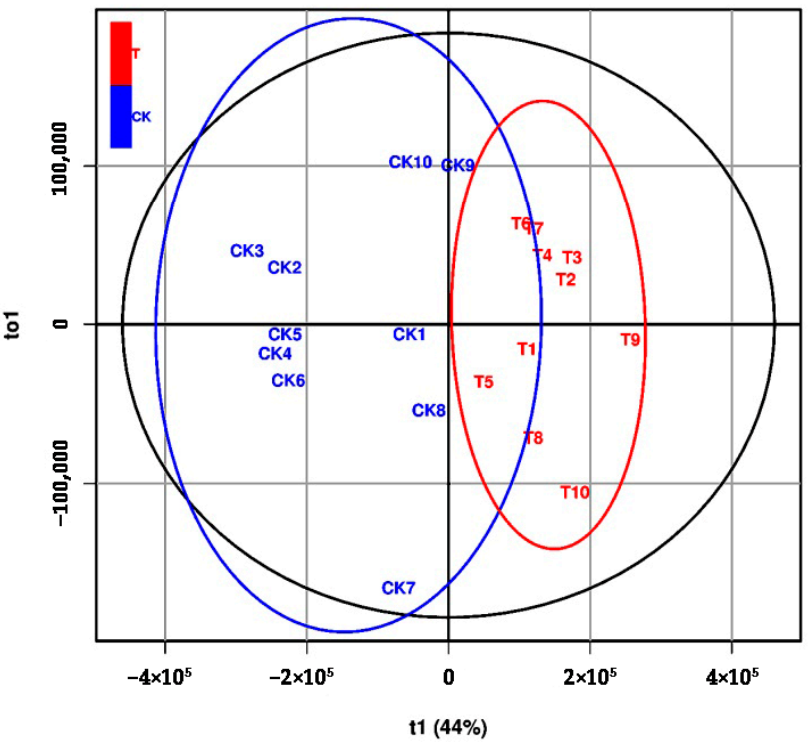

Scores (OPLS-DA)

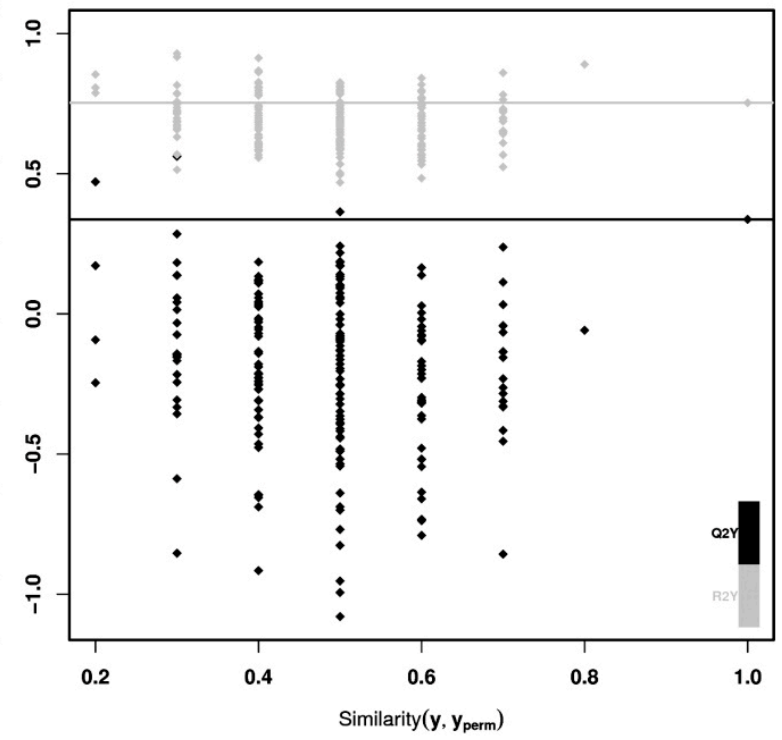

$\mathrm{pR} 2 \mathrm{Y}=0.055, \mathrm{pQ2}=0.005$

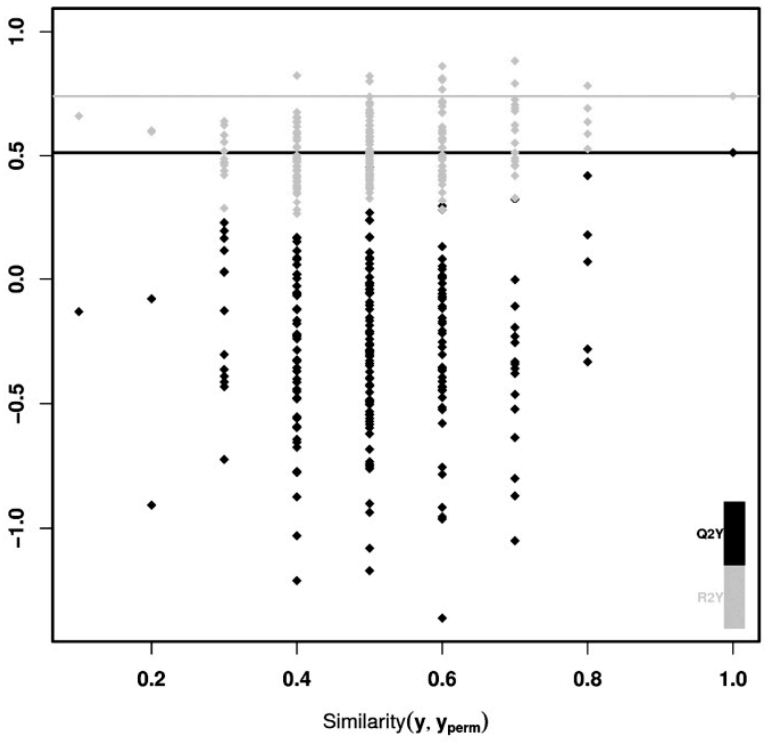

Figure 4. OPLS-DA (partial least squares discriminant analysis) score plots (left) with corresponding permutation test plots (right) derived from (a) positive ion mode (ESI+) and (b) negative ion mode (ESI-) in LC-MS metabolite profiles of C. sinica larvae.

\subsection{Changes in Metabolites and Metabolic Pathways of Differentially Abundant Metabolites}

Representative LC-MS total ion chromatograms (TICs) of C. sinica larvae tissue samples are shown in Figure 5. The shape and quantity of peaks between the $\mathrm{T}$ and $\mathrm{CK}$ treatments varied greatly. Approximately 13,672 and 10,947 metabolite peaks were deconvoluted in ESI+ and ESI- modes of LC-MS, respectively. The ESI+ usually detects N, $\mathrm{O}$, and $\mathrm{S}$-containing species and also some specific hydrocarbons, such as isoprene, terpenes, and aromatics as protonated neutral $\mathrm{MH}+$, whereas the ESI- detects acid including carboxylic acids $\mathrm{RCOOH}$ and inorganic acids and hydrosulfides as deprotonated neutral $[\mathrm{M}-\mathrm{H}]^{-}$[42]. A total of 3210 and 2026 remaining peaks in ESI+ and ESI- modes in LC-MS were further annotated using references in existing databases, respectively. After the exogenous compounds in LC-MS were removed, the differentially abundant metabolites were selected according to the VIP values from the OPLS-DA model (VIP $\geq 1$ ) and the corrected 
$p$ values from $t$-test $(p<0.05)$. There were 778 compounds in the ESI+ model, of which 357 were upregulated and 421 were downregulated. In ESI- mode, there were 391 compounds: 180 were upregulated and 211 were downregulated.
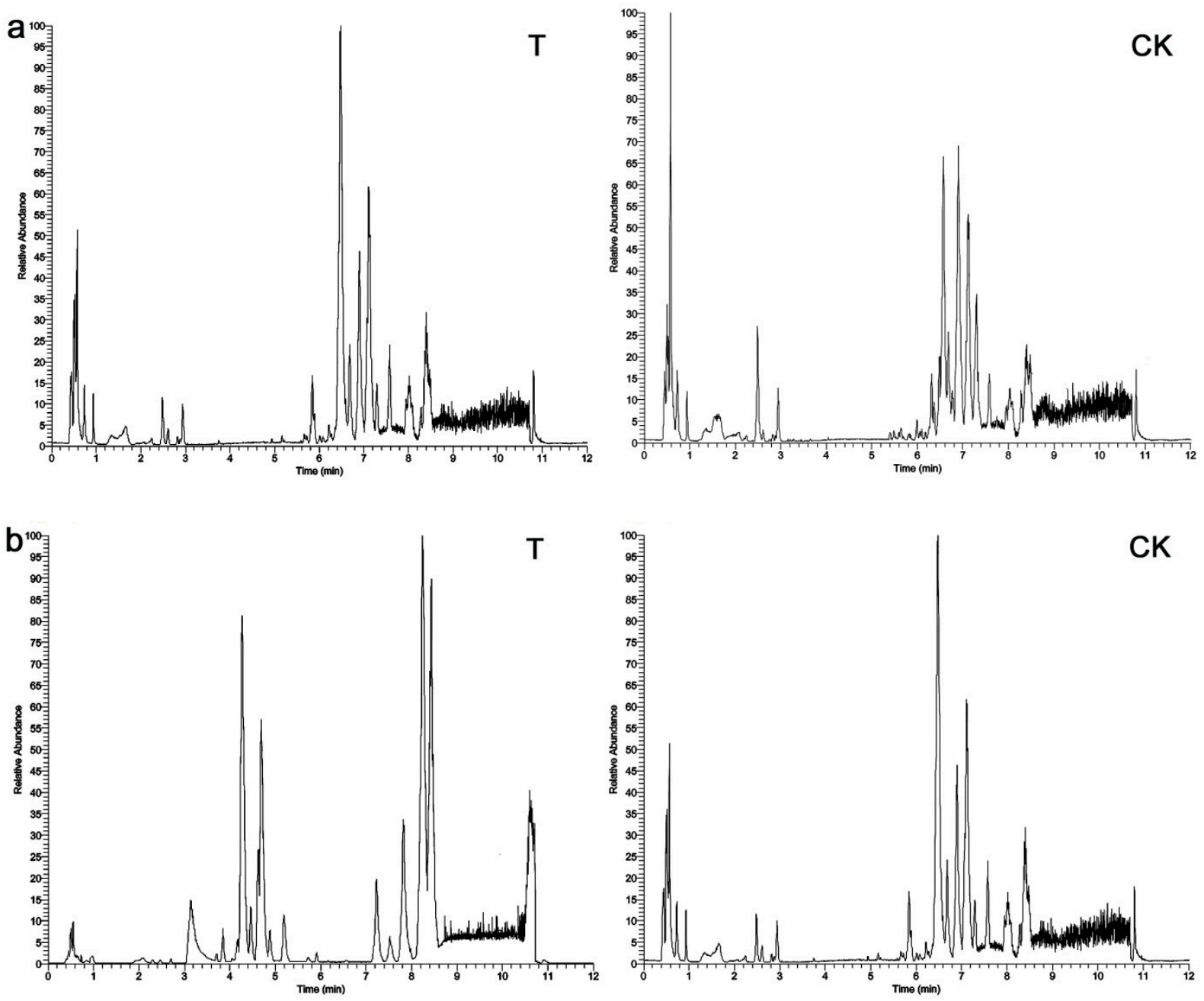

Figure 5. Representative total ion current (TIC) chromatograms of $C$. sinica larvae tissue extracts obtained from (a) positive ion mode (ESI+) and (b) negative ion mode (ESI-) in LC-MS. Left plots were treatment samples $(\mathrm{T})$, and right plots were control samples $(\mathrm{CK})$.

Table 1 shows some related metabolic pathways with representative differentially abundant metabolites and their upregulation and downregulation. Amino acids, carbohydrates, bile, lipids, membrane transports, cofactors and vitamins were primary metabolites that were affected in C. sinica larvae after ingestion of azadirachtin-treated P. xylostella larvae. The enrichment of pathways is presented in Figure 6. Rich factor refers to the ratio of the numbers of differentially abundant metabolites annotated in this pathway to the numbers of all metabolites annotated to the same pathway. The greater the rich factor, the greater the pathway enrichment. The $p$ value is another parameter for enrichment with a range from 0 to 1 , the closer to 0 , the more significance of the enrichment. As shown in Figure 6, biotin metabolism was significantly enriched, but the numbers of metabolites were much lower. Tryptophan metabolism was also significantly enriched with relatively higher metabolite numbers. Arginine and proline metabolism had a Rich factor of 0.33 with rather higher metabolite numbers. Lysine degradation had comparable Rich factors and also higher metabolite numbers. Additionally, beta-alanine metabolism was significantly relevant pathway of $C$. sinica larvae that were affected by ingestion of azadirachtin-treated P. xylostella larvae. 
Table 1. Differentially abundant metabolites identified in ESI+ and ESI- modes of LC-MS analysis of extracts derived from C. sinica larvae fed azadirachtin-treated P. xylostella larvae in contrast to those from the control treatment.

\begin{tabular}{|c|c|c|c|c|c|c|c|c|}
\hline Mode & KEGG Class & Pathway & Regulation & $p$-Value ${ }^{\dagger}$ & $\operatorname{VIP} \ddagger$ & Name & Formula & $\mathbf{M} / \mathbf{Z}^{\S}$ \\
\hline \multirow{24}{*}{ ESI+ } & \multirow{15}{*}{$\begin{array}{l}\text { Amino acid } \\
\text { metabolism }\end{array}$} & Glycine, serine, and threonine metabolism & down & $6.86 \times 10^{-3}$ & 11.98 & Choline & $\mathrm{C}_{5} \mathrm{H}_{13} \mathrm{NO}$ & 104.1068832 \\
\hline & & Arginine and proline metabolism & up & $9.49 \times 10^{-3}$ & 1.75 & Putrescine & $\mathrm{C}_{4} \mathrm{H}_{12} \mathrm{~N}_{2}$ & 89.10725487 \\
\hline & & Lysine degradation & down & $4.08 \times 10^{-2}$ & 1.33 & Cadaverine & $\mathrm{C}_{5} \mathrm{H}_{14} \mathrm{~N}_{2}$ & 103.122903 \\
\hline & & Tryptophan metabolism & down & $3.44 \times 10^{-2}$ & 1.11 & Indole & $\mathrm{C}_{8} \mathrm{H}_{7} \mathrm{~N}$ & 118.0650873 \\
\hline & & Lysine biosynthesis & down & $2.11 \times 10^{-6}$ & 2.07 & L-Saccharopine & $\mathrm{C}_{11} \mathrm{H}_{20} \mathrm{~N}_{2} \mathrm{O}_{6}$ & 277.1390289 \\
\hline & & Phenylalanine metabolism & down & $2.18 \times 10^{-2}$ & 5.22 & Phenylacetaldehyde & $\mathrm{C}_{8} \mathrm{H}_{8} \mathrm{O}$ & 121.0647704 \\
\hline & & Arginine biosynthesis & down & $5.84 \times 10^{-3}$ & 2.74 & L-Citrulline & $\mathrm{C}_{6} \mathrm{H}_{13} \mathrm{~N}_{3} \mathrm{O}_{3}$ & 176.1028923 \\
\hline & & Arginine and proline metabolism & up & $8.30 \times 10^{-4}$ & 11.94 & Spermidine & $\mathrm{C}_{7} \mathrm{H}_{19} \mathrm{~N}_{3}$ & 146.1651255 \\
\hline & & Tryptophan metabolism & down & $1.83 \times 10^{-2}$ & 5.89 & L-Kynurenine & $\mathrm{C}_{10} \mathrm{H}_{12} \mathrm{~N}_{2} \mathrm{O}_{3}$ & 209.0919249 \\
\hline & & Arginine and proline metabolism & down & $9.08 \times 10^{-3}$ & 4.49 & Agmatine & $\mathrm{C}_{5} \mathrm{H}_{14} \mathrm{~N}_{4}$ & 131.1290899 \\
\hline & & Arginine and proline metabolism & up & $3.60 \times 10^{-3}$ & 2.51 & 1-Pyrroline-4-hydroxy-2-carboxylate & $\mathrm{C}_{5} \mathrm{H}_{7} \mathrm{NO}_{3}$ & 130.0498415 \\
\hline & & Histidine metabolism & down & $2.19 \times 10^{-2}$ & 2.51 & Urocanic acid & $\mathrm{C}_{6} \mathrm{H}_{6} \mathrm{~N}_{2} \mathrm{O}_{2}$ & 139.0502099 \\
\hline & & Lysine degradation & up & $1.17 \times 10^{-2}$ & 2.85 & Deoxycarnitine & $\mathrm{C}_{7} \mathrm{H}_{15} \mathrm{NO}_{2}$ & 146.1175269 \\
\hline & & Lysine degradation & down & $1.27 \times 10^{-3}$ & 2.68 & L-Pipecolic acid & $\mathrm{C}_{6} \mathrm{H}_{11} \mathrm{NO}_{2}$ & 130.0862821 \\
\hline & & Cysteine and methionine metabolism & up & $2.01 \times 10^{-3}$ & 3.80 & Sulfite & $\mathrm{SO}_{3}{ }^{2-}$ & 83.084995 \\
\hline & \multirow{7}{*}{$\begin{array}{l}\text { Carbohydrate } \\
\text { metabolism }\end{array}$} & Glyoxylate and dicarboxylate metabolism & down & $2.99 \times 10^{-3}$ & 4.62 & L-threo-3-Methylaspartate & $\mathrm{C}_{5} \mathrm{H}_{9} \mathrm{NO}_{4}$ & 148.0603521 \\
\hline & & Amino sugar and nucleotide sugar metabolism & down & $1.80 \times 10^{-3}$ & 1.72 & N-Acetylneuraminate & $\mathrm{C}_{11} \mathrm{H}_{19} \mathrm{NO}_{9}$ & 310.1127173 \\
\hline & & Amino sugar and nucleotide sugar metabolism & up & $1.47 \times 10^{-2}$ & 1.72 & CDP-abequose & $\mathrm{C}_{15} \mathrm{H}_{25} \mathrm{~N}_{3} \mathrm{O}_{14} \mathrm{P}_{2}$ & 534.3283127 \\
\hline & & Pentose and glucuronate interconversions & down & $3.45 \times 10^{-4}$ & 16.41 & CDP-ribitol & $\mathrm{C}_{14} \mathrm{H}_{25} \mathrm{~N}_{3} \mathrm{O}_{15} \mathrm{P}_{2}$ & 538.3194126 \\
\hline & & Amino sugar and nucleotide sugar metabolism & down & $2.76 \times 10^{-3}$ & 1.13 & UDP-L-Ara4N & $\mathrm{C}_{14} \mathrm{H}_{23} \mathrm{~N}_{3} \mathrm{O}_{15} \mathrm{P}_{2}$ & 536.3039803 \\
\hline & & Amino sugar and nucleotide sugar metabolism & down & $7.69 \times 10^{-4}$ & 1.18 & CDP-4-dehydro-3,6-dideoxy-D-glucose & $\mathrm{C}_{15} \mathrm{H}_{23} \mathrm{~N}_{3} \mathrm{O}_{14} \mathrm{P}_{2}$ & 532.3185085 \\
\hline & & Amino sugar and nucleotide sugar metabolism & down & $4.66 \times 10^{-3}$ & 2.99 & N-Acetylmuramic acid 6-phosphate & $\mathrm{C}_{11} \mathrm{H}_{20} \mathrm{NO}_{11} \mathrm{P}$ & 374.2531432 \\
\hline & \multirow{2}{*}{ Digestive system } & Bile secretion & down & $1.26 \times 10^{-2}$ & 7.39 & L-Carnitine & $\mathrm{C}_{7} \mathrm{H}_{15} \mathrm{NO}_{3}$ & 162.1123783 \\
\hline & & Bile secretion & down & $3.80 \times 10^{-4}$ & 6.22 & Acyclovir & $\mathrm{C}_{8} \mathrm{H}_{11} \mathrm{~N}_{5} \mathrm{O}_{3}$ & 226.216309 \\
\hline
\end{tabular}


Table 1. Cont.

\begin{tabular}{|c|c|c|c|c|c|c|c|c|}
\hline Mode & KEGG Class & Pathway & Regulation & $p$-Value ${ }^{\dagger}$ & VIP $\ddagger$ & Name & Formula & $\mathrm{M} / \mathrm{Z}^{\S}$ \\
\hline & \multirow{3}{*}{$\begin{array}{l}\text { Lipid } \\
\text { metabolism }\end{array}$} & Glycerophospholipid metabolism & up & $1.57 \times 10^{-2}$ & 7.49 & sn-Glycero-3-phosphocholine & $\mathrm{C}_{8} \mathrm{H}_{21} \mathrm{NO}_{6} \mathrm{P}^{+}$ & 258.1097776 \\
\hline & & Glycerophospholipid metabolism & up & $4.97 \times 10^{-2}$ & 2.77 & LysoPC(16:1(9Z)) & $\mathrm{C}_{24} \mathrm{H}_{48} \mathrm{NO}_{7} \mathrm{P}$ & 494.3234809 \\
\hline & & Glycerophospholipid metabolism & up & $3.07 \times 10^{-2}$ & 3.58 & Glycerylphosphorylethanolamine & $\mathrm{C}_{5} \mathrm{H}_{14} \mathrm{NO}_{6} \mathrm{P}$ & 216.062969 \\
\hline & \multirow{2}{*}{$\begin{array}{l}\text { Membrane } \\
\text { transport }\end{array}$} & $\mathrm{ABC}$ transporters & up & $1.58 \times 10^{-3}$ & 1.84 & Ferrichrome & $\mathrm{C}_{27} \mathrm{H}_{42} \mathrm{FeN}_{9} \mathrm{O}_{12}$ & 741.5250124 \\
\hline & & $\mathrm{ABC}$ transporters & down & $1.28 \times 10^{-3}$ & 2.09 & Mannopine & $\mathrm{C}_{11} \mathrm{H}_{22} \mathrm{~N}_{2} \mathrm{O}_{8}$ & 311.3132994 \\
\hline & \multirow{4}{*}{$\begin{array}{l}\text { Metabolism } \\
\text { o cofactors } \\
\text { and vitamins }\end{array}$} & Porphyrin and chlorophyll metabolism & up & $4.05 \times 10^{-3}$ & 1.01 & Biliverdin & $\mathrm{C}_{33} \mathrm{H}_{34} \mathrm{~N}_{4} \mathrm{O}_{6}$ & 583.2537613 \\
\hline & & Biotin metabolism & down & $4.20 \times 10^{-3}$ & 1.06 & Biotin & $\mathrm{C}_{10} \mathrm{H}_{16} \mathrm{~N}_{2} \mathrm{O}_{3} \mathrm{~S}$ & 245.0953355 \\
\hline & & Thiamine metabolism & up & $2.49 \times 10^{-3}$ & 2.39 & Thiamin triphosphate & $\mathrm{C}_{12} \mathrm{H}_{19} \mathrm{~N}_{4} \mathrm{O}_{10} \mathrm{P}_{3} \mathrm{~S}$ & 506.2968678 \\
\hline & & Nicotinate and nicotinamide metabolism & down & $1.75 \times 10^{-2}$ & 1.09 & 2,3-Dimethylmaleate & $\mathrm{C}_{6} \mathrm{H}_{8} \mathrm{O}_{4}$ & 145.1335282 \\
\hline & $\begin{array}{l}\text { Metabolism } \\
\text { of other } \\
\text { amino acids }\end{array}$ & beta-Alanine metabolism & up & $3.18 \times 10^{-3}$ & 3.47 & Pantothenic acid & $\mathrm{C}_{9} \mathrm{H}_{17} \mathrm{NO}_{5}$ & 220.1178677 \\
\hline \multirow{12}{*}{ ESI- } & \multirow{4}{*}{$\begin{array}{l}\text { Amino acid } \\
\text { metabolism }\end{array}$} & Valine, leucine and isoleucine degradation & down & $3.54 \times 10^{-3}$ & 2.84 & L-VALINE & $\mathrm{C}_{5} \mathrm{H}_{11} \mathrm{NO}_{2}$ & 116.0717418 \\
\hline & & Lysine biosynthesis & down & $3.88 \times 10^{-3}$ & 3.80 & L-LYSINE & $\mathrm{C}_{6} \mathrm{H}_{14} \mathrm{~N}_{2} \mathrm{O}_{2}$ & 145.098347 \\
\hline & & Tryptophan metabolism & down & $1.95 \times 10^{-2}$ & 1.18 & 5-Hydroxyindoleacetic acid & $\mathrm{C}_{10} \mathrm{H}_{9} \mathrm{NO}_{3}$ & 190.0509535 \\
\hline & & Alanine, aspartate and glutamate metabolism & up & $2.46 \times 10^{-2}$ & 1.09 & Succinic acid semialdehyde & $\mathrm{C}_{4} \mathrm{H}_{6} \mathrm{O}_{3}$ & 101.0244019 \\
\hline & $\begin{array}{l}\text { Biosynthesis of } \\
\text { other secondary } \\
\text { metabolites }\end{array}$ & Caffeine metabolism & down & $5.30 \times 10^{-3}$ & 1.07 & 7-Methylxanthosine & $\mathrm{C}_{11} \mathrm{H}_{15} \mathrm{~N}_{4} \mathrm{O}_{6}$ & 298.2467506 \\
\hline & \multirow{7}{*}{$\begin{array}{l}\text { Carbohydrate } \\
\text { metabolism }\end{array}$} & Citrate cycle (TCA cycle) & down & $9.43 \times 10^{-3}$ & 1.64 & Succinic acid & $\mathrm{C}_{4} \mathrm{H}_{6} \mathrm{O}_{4}$ & 117.0193765 \\
\hline & & Pentose and glucuronate interconversions & up & $1.46 \times 10^{-3}$ & 1.60 & Ribitol & $\mathrm{C}_{5} \mathrm{H}_{12} \mathrm{O}_{5}$ & 151.0611315 \\
\hline & & Glycolysis / Gluconeogenesis & up & $2.63 \times 10^{-5}$ & 2.23 & D-Glycerate 3-phosphate & $\mathrm{C}_{3} \mathrm{H}_{7} \mathrm{O}_{7} \mathrm{P}$ & 184.9855899 \\
\hline & & Fructose and mannose metabolism & up & $4.08 \times 10^{-2}$ & 3.58 & Mannitol & $\mathrm{C}_{6} \mathrm{H}_{14} \mathrm{O}_{6}$ & 181.0717565 \\
\hline & & Amino sugar and nucleotide sugar metabolism & down & $2.78 \times 10^{-3}$ & 1.02 & $\begin{array}{l}\text { Uridine } \\
\text { diphosphate-N-acetylglucosamine }\end{array}$ & $\mathrm{C}_{17} \mathrm{H}_{27} \mathrm{~N}_{3} \mathrm{O}_{17} \mathrm{P}_{2}$ & 606.0741142 \\
\hline & & C5-Branched dibasic acid metabolism & up & $4.61 \times 10^{-2}$ & 1.54 & Itaconate, Itaconic acid & $\mathrm{C}_{5} \mathrm{H}_{6} \mathrm{O}_{4}$ & 129.0194034 \\
\hline & & Ascorbate and aldarate metabolism & up & $5.48 \times 10^{-3}$ & 1.48 & Threonic acid & $\mathrm{C}_{4} \mathrm{H}_{8} \mathrm{O}_{5}$ & 135.0299386 \\
\hline
\end{tabular}


Table 1. Cont.

\begin{tabular}{|c|c|c|c|c|c|c|c|c|}
\hline Mode & KEGG Class & Pathway & Regulation & $p$-Value ${ }^{+}$ & VIP $\ddagger$ & Name & Formula & $\mathbf{M} / \mathbf{Z}^{\S}$ \\
\hline & & Galactose metabolism & up & $9.68 \times 10^{-3}$ & 2.24 & Tagatose & $\mathrm{C}_{6} \mathrm{H}_{12} \mathrm{O}_{6}$ & 179.0560745 \\
\hline & & Pentose and glucuronate interconversions & down & $1.10 \times 10^{-3}$ & 2.43 & CDP-ribitol & $\mathrm{C}_{14} \mathrm{H}_{25} \mathrm{~N}_{3} \mathrm{O}_{15} \mathrm{P}_{2}$ & 536.3041792 \\
\hline & & Pentose and glucuronate interconversions & down & $3.65 \times 10^{-4}$ & 11.32 & CDP-ribitol & $\mathrm{C}_{14} \mathrm{H}_{25} \mathrm{~N}_{3} \mathrm{O}_{15} \mathrm{P}_{2}$ & 536.3053925 \\
\hline & & Amino sugar and nucleotide sugar metabolism & up & $8.30 \times 10^{-4}$ & 1.31 & CMP-pseudaminic acid & $\mathrm{C}_{22} \mathrm{H}_{34} \mathrm{~N}_{5} \mathrm{O}_{15} \mathrm{P}$ & 638.5000382 \\
\hline & $\begin{array}{l}\text { Energy } \\
\text { metabolism }\end{array}$ & Oxidative phosphorylation & down & $9.09 \times 10^{-3}$ & 1.12 & Pyrophosphate & $\mathrm{P}_{2} \mathrm{O}_{7}^{4-}$ & 176.935889 \\
\hline & \multirow{7}{*}{$\begin{array}{l}\text { Lipid } \\
\text { metabolism }\end{array}$} & Fatty acid biosynthesis & up & $2.72 \times 10^{-3}$ & 11.07 & Caprylic acid & $\mathrm{C}_{8} \mathrm{H}_{16} \mathrm{O}_{2}$ & 143.1077396 \\
\hline & & Fatty acid biosynthesis & down & $3.75 \times 10^{-3}$ & 10.03 & Palmitoleic acid & $\mathrm{C}_{16} \mathrm{H}_{30} \mathrm{O}_{2}$ & 253.2172625 \\
\hline & & Primary bile acid biosynthesis & up & $2.73 \times 10^{-3}$ & 5.33 & Taurine & $\mathrm{C}_{2} \mathrm{H}_{7} \mathrm{NO}_{3} \mathrm{~S}$ & 124.0073745 \\
\hline & & Fatty acid biosynthesis & up & $7.76 \times 10^{-3}$ & 5.94 & Palmitic acid & $\mathrm{C}_{16} \mathrm{H}_{32} \mathrm{O}_{2}$ & 255.2329072 \\
\hline & & alpha-Linolenic acid metabolism & down & $1.33 \times 10^{-3}$ & 5.58 & Linolenic Acid & $\mathrm{C}_{18} \mathrm{H}_{30} \mathrm{O}_{2}$ & 277.2171486 \\
\hline & & Linoleic acid metabolism & down & $8.66 \times 10^{-3}$ & 2.89 & 9-OxoODE & $\mathrm{C}_{18} \mathrm{H}_{30} \mathrm{O}_{3}$ & 293.2123043 \\
\hline & & Biosynthesis of unsaturated fatty acids & down & $6.24 \times 10^{-3}$ & 1.21 & Arachidic acid & $\mathrm{C}_{20} \mathrm{H}_{40} \mathrm{O}_{2}$ & 311.2954346 \\
\hline & $\begin{array}{l}\text { Membrane } \\
\text { transport }\end{array}$ & $\mathrm{ABC}$ transporters & up & $6.64 \times 10^{-3}$ & 4.01 & Ferrichrome & $\mathrm{C}_{27} \mathrm{H}_{42} \mathrm{FeN}_{9} \mathrm{O}_{12}$ & 739.5113096 \\
\hline & \multirow{3}{*}{$\begin{array}{l}\text { Metabolism of } \\
\text { cofactors and } \\
\text { vitamins }\end{array}$} & Folate biosynthesis & down & $3.34 \times 10^{-3}$ & 4.26 & $\begin{array}{l}\text { 2-Amino-4-hydroxy-6-(D-erythro-1,2,3- } \\
\text { trihydroxypropyl)-7,8- } \\
\text { dihydropteridine }\end{array}$ & $\mathrm{C}_{9} \mathrm{H}_{13} \mathrm{~N}_{5} \mathrm{O}_{4}$ & 254.2205895 \\
\hline & & $\begin{array}{l}\text { Ubiquinone and other } \\
\text { terpenoid-quinone biosynthesis }\end{array}$ & down & $7.16 \times 10^{-4}$ & 1.66 & $\begin{array}{l}(1 \mathrm{R}, 6 \mathrm{R})-6-H y d r o x y-2- \\
\text { succinylcyclohexa-2,4-diene-1- } \\
\text { carboxylate }\end{array}$ & $\mathrm{C}_{11} \mathrm{H}_{12} \mathrm{O}_{6}$ & 239.2015915 \\
\hline & & Folate biosynthesis & down & $3.34 \times 10^{-2}$ & 1.37 & Neopterin & $\mathrm{C}_{9} \mathrm{H}_{11} \mathrm{~N}_{5} \mathrm{O}_{4}$ & 252.2049325 \\
\hline & $\begin{array}{l}\text { Metabolism } \\
\text { of other } \\
\text { amino acids }\end{array}$ & beta-Alanine metabolism & up & $1.37 \times 10^{-2}$ & 1.77 & Pantothenic Acid $\left(B_{5}\right)$ & $\mathrm{C}_{9} \mathrm{H}_{17} \mathrm{NO}_{5}$ & 218.1033645 \\
\hline & Sensory system & $\begin{array}{l}\text { Inflammatory mediator } \\
\text { regulation of TRP channels }\end{array}$ & down & $2.82 \times 10^{-3}$ & 1.58 & Icilin & $\mathrm{C}_{16} \mathrm{H}_{13} \mathrm{~N}_{3} \mathrm{O}_{4}$ & 310.2830475 \\
\hline
\end{tabular}

KEGG is the major public pathway-related database that includes not only genes but metabolites. ${ }^{\dagger}$ Pathway enrichment analysis identified significantly enriched metabolic pathways or signal transduction pathways in differential metabolites comparing with the whole background. The calculating formula is as follows: $P=1-\sum_{i=0} \frac{\left(\begin{array}{c}M \\ i\end{array}\right)\left(\begin{array}{c}N-M \\ n-i\end{array}\right)}{(\text { Here } \mathrm{N} \text { is the }}$ $\left(\begin{array}{c}N \\ n\end{array}\right)$

number of all metabolites that with KEGG annotation, $\mathrm{n}$ is the number of differential metabolites in $\mathrm{N}$, $\mathrm{M}$ is the number of all metabolites annotated to specific pathways, and $\mathrm{m}$ is number of differential metabolites in M. $\ddagger$ A variable importance in projection score of OPLS model was applied to rank the metabolites that best distinguished between two groups. $\$$ Means mass-to-charge ratio 


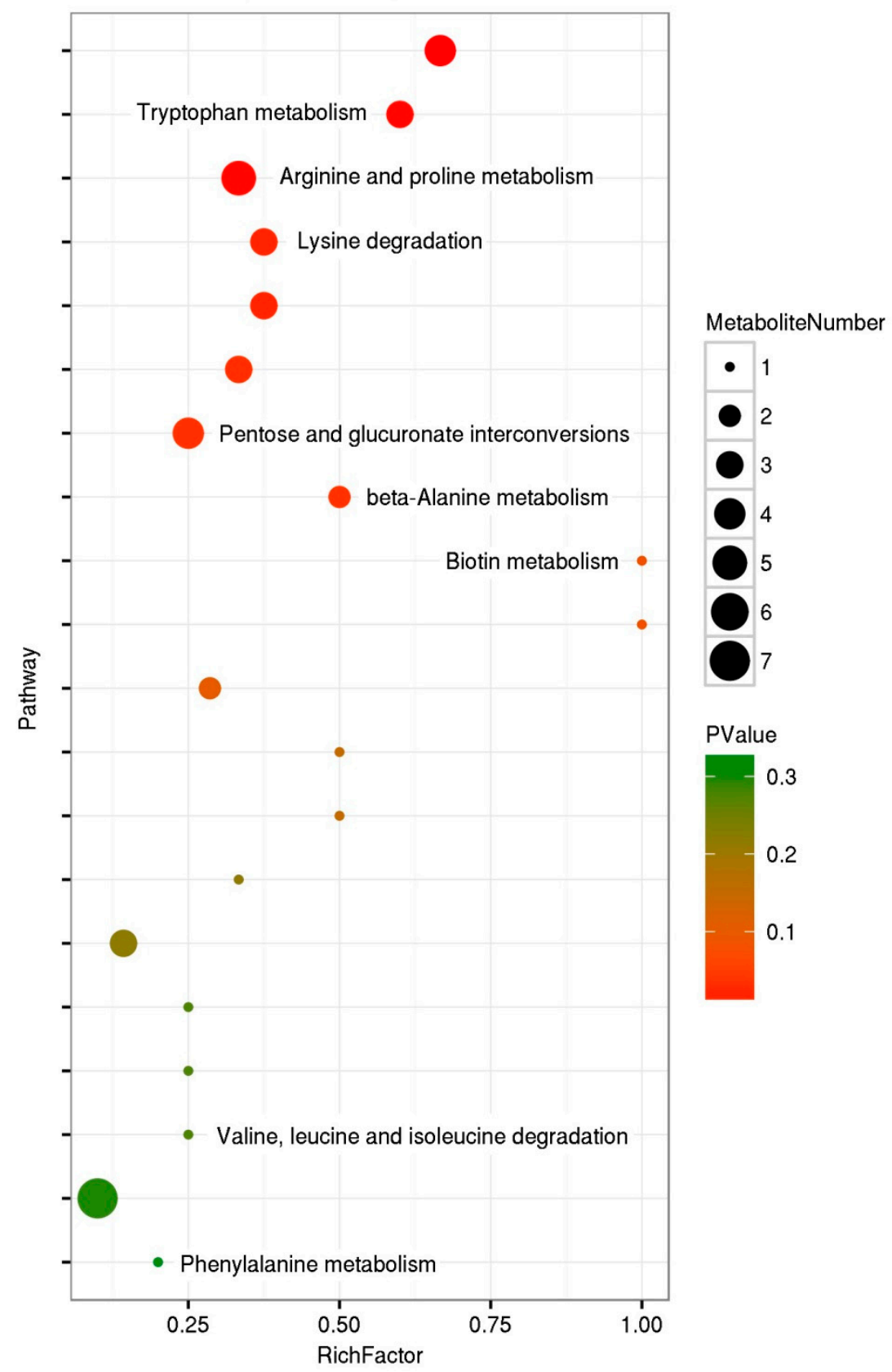

Figure 6. Metabolome map of significant metabolic pathways in C. sinica larvae affected by the ingestion of azadirachtin-treated P. xylostella larvae (pathway enrichment). Rich factor refers to the ratio of the number of annotated to this pathway in the differential metabolites to the number of annotated to this pathway in all metabolites. A larger rich factor indicates a higher degree of enrichment. $p$ values range from 0 to 1 , the closer to 0 , the more significance of the enrichment.

\section{Discussion}

\subsection{Metabolite Changes Adversely Affected C. sinica Development}

The present study showed that no mortality occurred in C. sinica larvae after consuming azadirachtin-treated P. xylostella larvae. However, their pupation and eclosion were significantly affected. Compared with the control treatment, $18 \%$ and $24 \%$ of the mature larvae were unable to perform pupation and eclosion, respectively (Figures 1 and 2). These results suggest that $C$. sinica larvae were able to obtain needed nutrients through digesting P. xylostella larvae to sustain their growth and even tolerate ingested azadirachtin, but the azadirachtin adversely affect $C$. sinica metabolism. As shown in Table 1 and Figure 6, over 
10,000 metabolites across more than 20 pathways, including the metabolism of carbohydrates, lipid amino acids, vitamins and their cofactors, and amino acids were changed in C. sinica larvae.

Amino acids are fundamental for synthesizing proteins and phospholipids, energy production, and involved in morphogenetic processes. In this study, lysine degradation, tryptophan metabolism, phenylalanine metabolism, arginine and proline metabolism, valine, leucine, and isoleucine degradation were substantially down-regulated (Table 1). The reduced metabolism of these amino acids could significantly impair $C$. sinica growth and development.

The carbohydrate metabolism is essential for cellular energy balance and for the biosynthesis of new cellular building blocks [43]. In this study, 10 carbohydrate pathways were down-regulated, and eight pathways were upregulated in both ESI+ and ESImodes (Table 1). Among them, succinic acid was a differentially enriched metabolite in tricarboxylic acid (TCA) cycles. The TCA cycle, known as the citric acid cycle, has an important function that involves the intermediate compounds for the synthesis of amino acids and fatty acids and the formation of large quantities of adenosine triphosphate (ATP) that provides energy for various biological processes [24]. The downregulation of succinic acids of carbohydrate metabolites could cause a shortage of intermediate compounds and energy in azadirachtin-ingested C. sinica larvae, impairing their growth and development. Additionally, the amino sugar and nucleotide sugar metabolism pathway was enriched in azadirachtin-ingested C. sinica larvae. D-glycerate 3-phosphate was also among the differentially enriched metabolites in glycolysis/gluconeogenesis pathway. Glycolysis and gluconeogenesis are metabolic processes responsible for glucose degradation or glucose synthesis, respectively [44].

Ingestion of azadirachtin-treated P. xylostella larvae also affected the metabolism of vitamins and their cofactor in $C$. sinica larvae. Biotin is an essential substance for insects and affects the development of advanced larvae and pupae. The biotin metabolism pathway was significantly enriched in C. sinica larvae. The downregulation of this metabolite could adversely affect normal metabolism and $C$. sinica development.

Glycolysis is the main metabolic pathway of carbohydrates, such as galactose and fructose [44]. As an intermediate in both glycolysis and gluconeogenesis, the change in the relative content of D-glycerate 3-phosphate could also affect the generation of intermediate compounds and energy to maintain normal biological processes. Furthermore, the pathways of pentose and glucuronate interconversions, C-5 branched dibasic acid metabolism, ascorbate, and aldarate metabolism were enriched in azadirachtin-ingested C. sinica. Such a series of changes in carbohydrate metabolisms would affect the energy supply of $C$. sinica larvae, thus their development. Lipids are of vital importance to insects as energy sources and substrates for embryogenesis and development, pupation, metamorphosis, and other activities [45]. They are important components of insect cell membrane and also precursors of many insect pheromones [45]. Azadirachtin could influence the quantity and relative composition of fatty acids [30]. In the present study, 11 lipids or lipid-like metabolites were found to be differentially abundant, of which seven were upregulated, and four were down-regulated. The downregulated included palmitoleic acid, linolenic acid, 9-hydeoxyoctadecadienoic acid (9-OxoODE), and arachidic acid. Linolenic acid plays an important role in insect reproduction as it is a key constitute of oocyte dry mass and the major energy source for embryo development. The linolenic acid has been documented to be required for developing Heliothines subflexa [46]. The reduction in metabolism of linolenic acid in azadirachtin-ingested $C$. sinica larvae may potentially affect the pupation and eclosion, which required further confirmation.

\subsection{Key Metabolic Pathways Affected by Feeding on Azadirachtin-Treated P. xylostella Larvae}

The aforementioned analyses provide an overall spectrum of metabolite changes in C. sinica after ingestion of azadirachtin-treated P. xylostella larvae. The next question would be which metabolic pathways might be specifically implicated in the reduced percentages 
in pupation and eclosion C. sinica. Through the KEGG pathway analysis of the differentially abundant metabolites, the disturbed metabolic pathways caused by the consumption of azadirachtin-treated P. xylostella larvae were analyzed. A working model was constructed using the reference map deposited in the KEGG database (Figure 7). It was noticed that 20 differential metabolites were related to amino acid metabolic pathways. Among them, 15 metabolites were down-regulated. These results could imply that the ingestion of azadirachtin-treated $P$. xylostella larvae might result in the impairment in hydrolyzing proteins in C. sinica resulting in an insufficient supply of amino acids or directly affect amino acid metabolisms. Amino acids, particularly the essential ones are fundamental for insect growth and development [47]. A distinct biochemical characteristic of insects is their higher levels of free amino acids in the hemolymph [48], and the likely utilization of the free amino acids as silk protein synthesis to produce cocoon [49]. Furthermore, the eclosion is controlled by three peptide hormones: eclosion hormone, ecdysis-triggering hormone, and crustacean cardioactive peptide [50,51]. The reduction of free amino acids could hamper both pupation and eclosion of $C$. sinica.

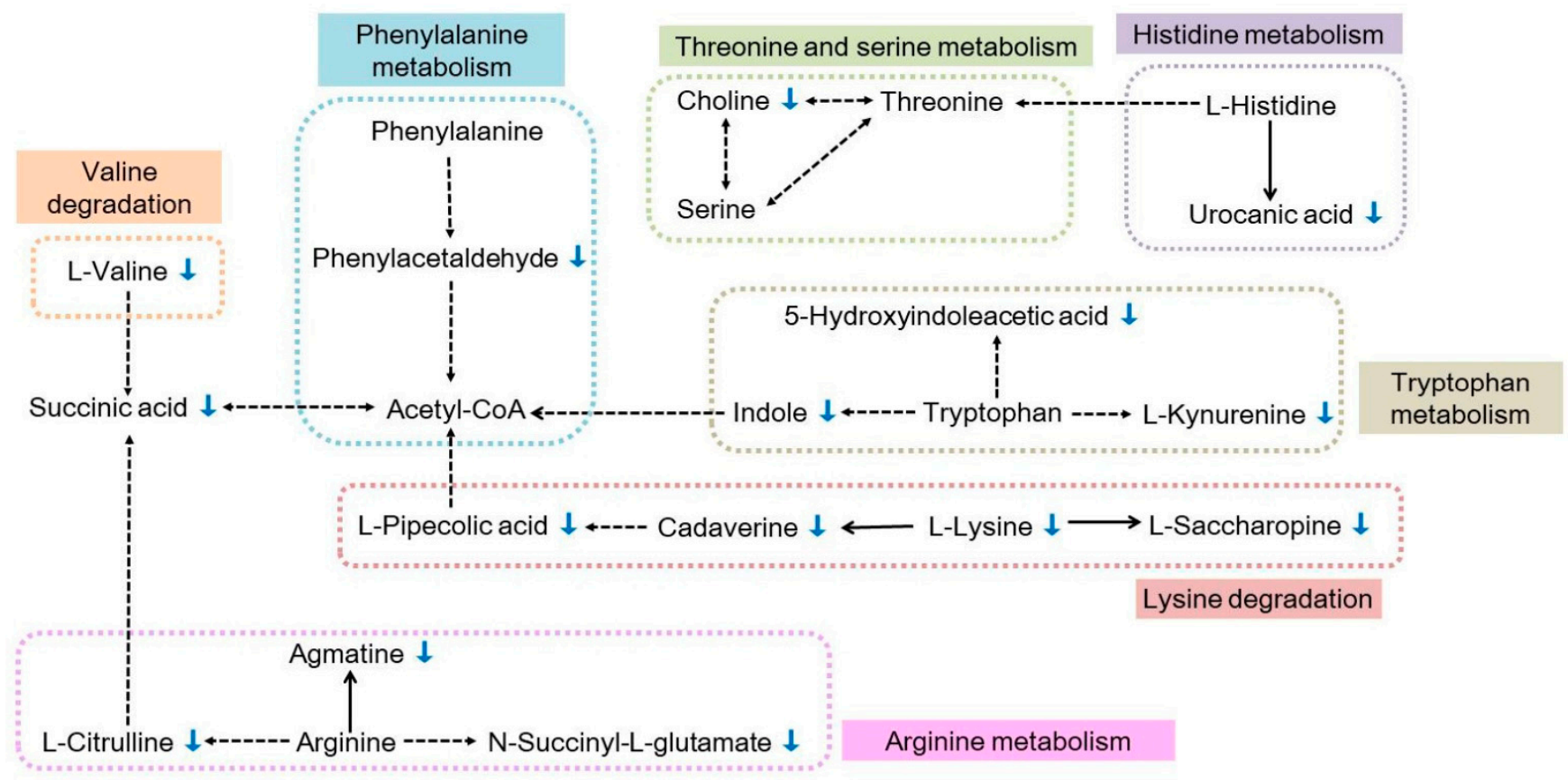

Figure 7. Metabolic pathways related to amino acid metabolism in C. sinica larvae affected by the ingestion of azadirachtin-treated P. xylostella larvae. The blue arrows indicate decreased metabolites.

As shown in Figure 7, a majority of essential amino acid metabolisms were downregulated. A limited supply of tryptophan resulted in the decrease in the contents of indole, L-kynurenine, and 5-hydroxyindoleacetic acid. The downregulation of these compounds could limit the biosynthesis of acetyl-CoA, affecting the TCA cycle. It is worth mentioning that metabolites of the kynurenic pathway generally reach to peak concentrations in insects during pupation $[52,53]$. The reduced availability of kynurenine could impair pupation in C. sinica. Limited availability of lysine caused reduced biosynthesis of cadaverine and L-pipecolic acid. The downregulation of cadaverine also affected acetyl-CoA biosynthesis, subsequently affecting the TCA cycle. In the arginine metabolism pathway, low arginine in cells resulted in reduced synthesis of N-succinyl-L-glutamate, L-citrulline, and agmatine. Arginine can be converted to proline. Proline was a major substrate used in insect flight metabolism, which is known as the fuel of insect flight [54]. Choline was downregulated, which could indirectly affect the metabolism of serine and threonine. Pyruvate, an indirect derivative of choline, also from glycolysis is regarded as a key metabolite producing valine [55]. Valine also affects acetyl-CoA. L-valine was significantly low in C. sinica. Taken 
together, at the time of requiring higher levels of free amino acids in the hemolymph, the reduced amino acid metabolisms, particularly the essential ones significantly affected the pupation and eclosion of $C$. sinica.

\subsection{Precautions When Azadirachtin and C. sinica Are Used in IPM}

The changes in a wide range of metabolites in C. sinica larvae suggest that the action mode of azadirachtin is multifaceted with multiple biological targets. Thus, precautions should be taken when azadirachtin and C. sinica are to be used in IPM. Although this study was mainly focused on metabolites without further analysis of the biological influence of these molecular alterations on natural enemies, our data did document that $C$. sinica larvae after ingestion of larvae of $P$. xylostella treated with azadirachtin at $2.00 \mathrm{mg} / \mathrm{L}$ significantly reduced pupation and eclosion. Such adverse effects were related to the substantial changes in metabolomic profile of $C$. sinica. As mentioned previously, the premise for the use of pesticides, even botanical ones, in IPM is ascertaining their compatibility with beneficial predators. Our study showed azadirachtin and C. sinica are not compatible, which primarily agrees with the results of $C$. claveri in responses to azadirachtin [18-21]. Commercially, azadirachtin has been applied at much higher concentrations ranging from 5 to $100 \mathrm{mg} / \mathrm{L}$ [56]. Thus, detrimental effects to beneficial insects could be even severer. However, this does not exclude the use of azadirachtin and C. sinica at different time periods. Nevertheless, our study has raised the compatibility question between the two control tactics. Further studies are needed to identify specific mechanisms underlying the reduced pupation and eclosion of $C$. sinica larvae, effects on mating and oviposition of adults, and the relationship between azadirachtin concentrations and metabolite changes as well as threshold concentrations of azadirachtin to $C$. sinica for potentially better use of the two tactics for pest management.

\section{Materials and Methods}

\subsection{Chrysopa sinica and Plutella xylostella}

Chrysopa sinica and Plutella xylostella were raised in the insect rearing facility of the Key Laboratory of Natural Pesticide and Chemical Biology, Ministry of Education, South China Agricultural University, Guangzhou, China. C. sinica larvae were fed larvae of P. xylostella, and the adults were fed on a diet of P. xylostella larvae, along with $15 \%$ honey water, and yeast powder. The larvae of $P$. xylostella were fed leaves of the host cabbage (Brassica oleracea L.) plants, and the adults were fed $15 \%$ honey water. The temperature in the insect rearing facility was $25 \pm 1{ }^{\circ} \mathrm{C}$, relative humidity was $60 \pm 5 \%$, and a light-dark cycle of $16 \mathrm{~h}$ and $8 \mathrm{~h}$.

\subsection{Chemical Reagents and Instruments}

Reagents including methanol, acetonitrile, ammonium acetate, ammonium hydroxide, and formic acid were purchased from CNW Technologies (ANPEL Laboratory Technologies, Inc. Shanghai, China). The internal standards of 2-chloro-L-phenylalanine was purchased from Shanghai Hengbai Biotech Co., Ltd. (Shanghai, China), and azadirachtin (>90\%) were provided by Associate Professor Yongqing Tian at the South China Agricultural University.

Major instruments used in this study included ultra-high performance liquid chromatography (UHPLC) (Agilent Technologies, Santa Clara, CA, USA) coupled with Q Exactive Focus mass spectrometer (MS) (Thermo Fisher Scientific, Waltham, MA, USA), centrifuge, scales, grinding mill, water purification, ultrasound instrument, and column (ACQUITY UPLC HSS T3 $1.7 \mu \mathrm{m}, 2.1 \times 100 \mathrm{~mm}$ ).

\subsection{Experimental Procedures and Samples Collection}

Cabbage plants were singly grown in $15-\mathrm{cm}$ pots filled with a peat-based potting substrate. When plants were at a stage of 10 leaves, 20 plants with a uniform growth size were randomly selected. The third instar larvae of P. xylostella were placed on cabbage leaves, 50 larvae per plant. Azadirachtin stock solution $(10,000 \mu \mathrm{g} / \mathrm{mL})$ was made by 
dissolving it in acetone. The stock solution was diluted with water resulting in a working solution of azadirachtin at $2.00 \mathrm{mg} / \mathrm{L}$, which was sprayed on leaves of 10 plants $(5 \mathrm{~mL}$ per plant) as azadirachtin treatment $(\mathrm{T})$. The other 10 plants were sprayed with the same concentration of acetone $(0.02 \%)$ in the same volume per plant as control treatment (CK). After the P. xylostella larvae had eaten the treated cabbage leaves for $12 \mathrm{~h}$ (Figure 1a), the third instar larvae of $C$. sinica were released and fed continuously with P. xylostella larvae from $\mathrm{T}$ and $\mathrm{CK}$ plants for 5 days, respectively (Figure $1 \mathrm{~b}$ ). The experiment was arranged as a complete randomized design with 10 replications. Five days later, more than fifty larvae of $C$. sinica were collected from each plant, quickly frozen in liquid nitrogen, and stored at $-80{ }^{\circ} \mathrm{C}$. The stored larvae samples were ground into a fine powder in liquid nitrogen and freeze-dried for $24 \mathrm{~h}$ until extraction.

To monitor the development of $C$. sinica, the pupation and eclosion of $C$. sinica larvae on cabbage plants of the two treatments were observed. After 10 days, when a complete white round cocoon was formed, the pupation was considered complete (Figure 1c). After 20 days, the adults broke out of the cocoon and spread their wings; they were deemed to have completed their emergence (Figure 1d). The experiment was arranged as a randomized complete block design with three replications (three blocks), each block had 50 larvae. The proportion of pupation and eclosion were calculated and analyzed using SPSS software platform (25.0) (IBM Corporation, Somers, NY, USA), and means were separated based on Tukey's HSD (honestly significant different) test at $p<0.01$ and $p<0.001$ levels.

\subsection{Metabolites Extraction and Detection}

The ground samples of control (CK) and azadirachtin treatment (T), $100 \mathrm{mg}$ each, 10 replicates per treatment, were placed into Eppendorf tubes, respectively. To each tube was added $300 \mu \mathrm{L}$ methanol and $20 \mu \mathrm{L}$ 2-chloro-L-phenylalanine, the samples were vortexed for $30 \mathrm{~s}$ and sonicated for $5 \mathrm{~min}$ in the ice-water bath. The homogenate and sonicate circles were repeated for 3 times, followed by incubation at $-20^{\circ} \mathrm{C}$ for $1 \mathrm{~h}$ and centrifugation at $13,000 \mathrm{rpm}$ and $4{ }^{\circ} \mathrm{C}$ for $15 \mathrm{~min}$. The resulting supernatants were transferred to LC-MS vials and stored at $-80^{\circ} \mathrm{C}$ until analysis.

The quality control (QC) sample was prepared by mixing an equal aliquot of the supernatants from all of the samples to analyze the repeatability of samples under the same processing method. In the process of analysis, one quality control sample was inserted every 6-10 test analysis samples to monitor the repeatability of the analysis process.

The platform for LC-MS analysis consisted of an UHPLC system (1290, Agilent Technologies) with a UPLC HSS T3 column coupled to Q Exactive Orbitrap mass spectrometer (QEO MS) (Thermo Fisher Scientific). The supernatant $(200 \mu \mathrm{L})$ was taken into the sample bottle $(2 \mathrm{~mL})$, respectively.

Mobile phase conditions were set as follows: the mobile phase A was $0.1 \%$ formic acid in water for positive, and $5 \mathrm{mmol} / \mathrm{L}$ ammonium acetate in water for negative (adjusted the $\mathrm{PH}$ value to 9.0 with ammonia), and the mobile phase $\mathrm{B}$ was acetonitrile. The elution gradient of the mobile phase was shown in supplementary file, Table S1.

Mass spectrometry conditions included the use of QEO MS to collect MS and MS/MS data with the electrospray (ESI) source conditions set as follows: spray voltage as $3800 \mathrm{~V}$ for positive or $-3100 \mathrm{~V}$ for negative, capillary temperature $320^{\circ} \mathrm{C}$, sheath gas flow rate as $45 \mathrm{Arb}$, aux gas flow rate as $15 \mathrm{Arb}$, full MS resolution as 70,000, MS/MS resolution as 17,500 , strength of collision energy as 3 , collision energy as $20 / 40 / 60 \mathrm{eV}$, scanning scope as $70-1000 \mathrm{~m} / \mathrm{z}$, scan rate as $7 \mathrm{~Hz}$.

\subsection{Data Preprocessing and Multivariate Statistical Analysis}

The original LC-MS data files were converted to the mzML format by using ProteoWizard and processed by R package XCMS (version 3.2), including retention time alignment, peak detection, peak matching, and peak integration. The data were then filtered by the following criterion: sample numbers containing a metabolite were less than $50 \%$ of all sample numbers in a group. OSI-SMMS (version 1.0, Dalian Chem Data Solution Information 
Technology Co. Ltd, Dalian, China) was used for peak annotation after data processing with in-house MS/MS database.

To initially visualize the differences between different groups of samples, the principal component analysis (PCA) was applied. PCA analysis is an unsupervised multidimensional statistical analysis method that describes the characteristics of the original data set by compressing the original data into countless principal components, which can reflect the overall metabolic difference between each group of samples and the size of variation between the group samples. Partial least squares discriminant analysis (PLS-DA), as a supervised multivariate statistical analysis method, was used to distinguish the metabolomics profile of two groups by screening variables correlated to class memberships in which class memberships were coded in matrix form into Y [57]. Orthogonal projection to latent structures-discriminant analysis (OPLS-DA) is an extension of PLS-DA which incorporates an orthogonal signal correction (OSC) filter into a PLS model. The model quality was assessed based on cross-validation and permutation test [58]. The variable importance in projection (VIP) score of OPLS-DA model and $t$-test as a univariate analysis were applied to rank the metabolites that best distinguished the different groups in this study. Those with VIP $\geq 1$ and a $p$-value of $t$-test $<0.05$ were considered differential metabolites between two groups [59].

\subsection{KEGG Pathway Analysis}

After the metabolites were found, the metabolites were mapped to KEGG metabolic pathways for pathway analysis and enrichment analysis [60]. The main biochemical metabolic pathways and signal transduction pathways in differential metabolites were analyzed in this study. Significantly enriched metabolic pathways or signal transduction pathways in differential metabolites comparing with the whole background were identified through pathway enrichment analysis.

\section{Conclusions}

Azadirachtin as a botanical pesticide has been increasingly used for control of insect pests. This study investigated responses of predator $C$. sinica larvae after ingestion of P. xylostella larvae treated with azadirachtin, mainly at the metabolite levels. No mortality occurred in C. sinica larvae after consuming azadirachtin-treated P. xylostella larvae, but the percentages of pupation and eclosion of $C$. sinica were significantly reduced. Metabolomic analysis showed that azadirachtin has effects on the metabolism of amino acids, carbohydrates, lipid, cofactors and vitamins of $C$. sinica larvae. These effects may impair the growth and development of $C$. sinica, resulting in reduced pupation and eclosion percentages. Our studies for the first time documented substantial metabolite changes in $C$. sinica larvae after ingestion of azadirachtin-treated $P$. xylostella larvae and raise a question about the compatibility between azadirachtin and C. sinica in control of insect pests through IPM.

Supplementary Materials: The following supporting information can be downloaded at: https: / / www.mdpi.com/article/10.3390/metabo12020158/s1, Table S1: The elution gradient of the mobile phase in LC-MS analysis.

Author Contributions: Conceptualization, P.Z., J.C. and Z.Z.; software, P.Z. and Y.Z.; validation, Y.Z. and D.Q.; investigation, P.Z., Y.Z. and D.Q.; resources, P.Z.; data curation, P.Z. and J.C.; writingoriginal draft preparation, P.Z. and J.C.; writing-review and editing, P.Z., J.C. and D.Q.; visualization, P.Z.; supervision, J.C. and Z.Z.; funding acquisition, Z.Z. All authors have read and agreed to the published version of the manuscript.

Funding: This research was funded by the Key-Area Research and Development Program of Guangdong Province (grant number 2020B020224002) and the Guangdong Provincial Special Fund for Modern Agriculture Industry Technology Innovation Teams (grant number 2020KJ122).

Institutional Review Board Statement: Not applicable.

Informed Consent Statement: Not applicable. 
Data Availability Statement: Data is contained within the article or Supplementary Materials.

Acknowledgments: We appreciate Yongqing Tian from the South China Agricultural University who provided us azadirachtin material.

Conflicts of Interest: The authors declare no conflict of interest.

\section{References}

1. Ehler, L.E. Integrated pest management (IPM): Definition, historical development and implementation, and the other IPM. Pest Manag. Sci. 2006, 62, 787-789. [CrossRef]

2. Bueno, A.D.F.; Carvalho, G.A.; Santos, A.C.D.; Sosa-Gómez, D.R.; Silva, D.M.D. Pesticide selectivity to natural enemies: Challenges and constraints for research and field recommendation. Ciência Rural 2017, 47, 1-10. [CrossRef]

3. Martínez-Romero, A.; Ortega-Sánchez, J.L.; Hernández-González, S.I.; Olivas-Calderón, E.H.; Alba-Romero, J.J. Application of neem tree in agriculture, industry, medicine, and environment: A review. Afr. J. Tradit. Complementary Altern. Med. 2016, 13, 191-198. [CrossRef]

4. Isman, M.B. Botanical insecticides, deterrents, and repellents in modern agriculture and an increasingly regulated world. Annu. Rev. Entomol. 2006, 51, 45-66. [CrossRef] [PubMed]

5. Zanuncio, J.C.; Mourão, S.A.; Martínez, L.C.; Wilcken, C.F.; Ramalho, F.S.; Plata-Rueda, A.; Soares, M.A.; Serrão, J.E. Toxic effects of the neem oil (Azadirachta indica) formulation on the stink bug predator, Podisus nigrispinus (Heteroptera: Pentatomidae). Sci. Reps. 2016, 6, 1-8. [CrossRef]

6. Ahmad, N.; Ansari, M.S.; Hasan, F. Effects of neem-based insecticides on Plutella xylostella (Linn.). Crop Prot. 2012, 34, 18-24. [CrossRef]

7. Mordue, A.J.; Blackwell, A. Azadirachtin: An update. J. Insect Physiol. 1993, 39, 903-924. [CrossRef]

8. Schmutterer, H. Potential of azadirachtin-containing pesticides for integrated pest control in developing and industrialized countries. J. Insect Physiol. 1988, 34, 713-719. [CrossRef]

9. Vasanthakumar, D.; Babu, A.; Shanmugapriyan, R.; Subramaniam, S.R. Impact of Azter (azadirachtin 0.15\% EC), a neem-based pesticide, against tea red spider mite, Oligonychus coffeae Neitner (Acarina: Tetranychidae), and its natural enemies. Int. J. Acarol. 2013, 39, 140-145. [CrossRef]

10. Vinuela, E.; Adán, A.; Smagghe, G.; Gonzalez, M.; Medina, M.P.; Budia, F.; Vogt, H.; Estal, P.D. Laboratory effects of ingestion of azadirachtin by two pests (Ceratitis capitata and Spodoptera exigua) and three natural enemies (Chrysoperla carnea, Opius concolor and Podisus maculiventris). Biocontrol Sci. Technol. 2000, 10, 165-177. [CrossRef]

11. Viñuela, E.; Medina, M.P.; Schneider, M.; González, M.; Budia, F.; Adán, A.; Del Estal, P. Comparison of side-effects of spinosad, tebufenozide and azadirachtin on the predators Chrysoperla carnea and Podisus maculiventris and the parasitoids Opius concolor and Hyposoter didymator under laboratory conditions. Bulletin IOBC/WPRS 2001, 24, 25-34.

12. Lima, D.B.; Melo, J.W.S.; Guedes, N.M.P.; Gontijo, L.M.; Guedes, R.N.C.; Gondim Jr, M.G.C. Bioinsecticide-predator interactions: Azadirachtin behavioral and reproductive impairment of the coconut mite predator Neoseiulus baraki. PLoS ONE 2015, 10, e118343. [CrossRef] [PubMed]

13. Zhang, Y.; Xie, Y.; Xue, J.; Yang, X.; Gong, S. Response of a predatory insect, Chrysopa sinica, toward the volatiles of persimmon trees infested with the herbivore, Japanese wax scale. Int. J. Ecol. 2012, 2012, 653869. [CrossRef]

14. Gao, F.; Chen, F.; Ge, F. Elevated CO2 lessens predation of Chrysopa sinica on Aphis gossypii. Entomol. Exp. Appl. 2010, 135, 135-140. [CrossRef]

15. Shu, M.; Liu, W.; Feng, L.; Mou, L.; Ma, N.; Wang, P. Study on the functional response of Chrysopa sinica Tjeder to predation of the eggs of Leptinotarsa decemlineata Say. Xinjiang Agri. Sci. 2011, 48, 328-333.

16. Liu, Z.; Wyckhuys, K.A.; Wu, K. Migratory adaptations in Chrysoperla sinica (Neuroptera: Chrysopidae). Environ. Entomol. 2011, 40, 449-454. [CrossRef]

17. Medina, P.; Budia, F.; Tirry, L.; Smagghe, G.; Vinuela, E. Compatibility of spinosad, tebufenozide and azadirachtin with eggs and pupae of the predator Chrysoperla carnea (Stephens) under laboratory conditions. Biocontrol Sci. Technol. 2001, 11, 597-610. [CrossRef]

18. Ahmad, M.; Ossiewatsch, H.R.; Basedow, T. Effects of neem-treated aphids as food/hosts on their predators and parasitoids. J. Appl. Entomol. 2003, 127, 458-464. [CrossRef]

19. Medina, P.; Budia, F.; Del Estal, P.; Vinuela, E. Influence of azadirachtin, a botanical insecticide, on Chrysoperla carnea (Stephens) reproduction: Toxicity and ultrastructural approach. J. Econ. Entomol. 2004, 97, 43-50. [CrossRef] [PubMed]

20. Scudeler, E.L.; Dos Santos, D.C. Effects of neem oil (Azadirachta indica A. Juss) on midgut cells of predatory larvae Ceraeochrysa claveri (Navás, 1911)(Neuroptera: Chrysopidae). Micron 2013, 44, 125-132. [CrossRef]

21. Scudeler, E.L.; Padovani, C.R.; Dos Santos, D.C. Effects of neem oil (Azadirachta indica A. Juss) on the replacement of the midgut epithelium in the lacewing Ceraeochrysa claveri during larval-pupal metamorphosis. Acta Histochem. 2014, 116, 771-780. [CrossRef] [PubMed]

22. Mordue, A.J. Present concepts of the mode of action of azadirachtin from neem. In Neem: Today and in the New Millennium; Springer: Berlin/Heidelberg, Germany, 2004; pp. 229-242. 
23. Nisbet, A.J. Azadirachtin from the neem tree Azadirachta indica: Its action against insects. An. Soc. Entomológica Brasil 2000, $29,615-632$.

24. Zhou, Y.; Zhang, P.W.; Chen, X.T.; Liu, B.J.; Cheng, D.M.; Zhang, Z.X. Integrated LC-MS and GC-MS-based untargeted metabolomics studies of the effect of azadirachtin on Bactrocera dorsalis larvae. Sci. Rep. 2020, 10, 1-11. [CrossRef]

25. Sengottayan, S. Physiological and biochemical effect of neem and other Meliaceae plants secondary metabolites against Lepidopteran insects. Front. Physiol. 2013, 4, 359.

26. Lai, D.; Jin, X.; Wang, H.; Yuan, M.; Xu, H. Gene expression profile change and growth inhibition in Drosophila larvae treated with azadirachtin. J. Biotechnol. 2014, 185, 51-56. [CrossRef] [PubMed]

27. Wang, H.; Lai, D.; Yuan, M.; Xu, H. Growth inhibition and differences in protein profiles in azadirachtin-treated Drosophila melanogaster larvae. Electrophoresis 2014, 35, 1122-1129. [CrossRef]

28. Rharrabe, K.; Amri, H.; Bouayad, N.; Sayah, F. Effects of azadirachtin on post-embryonic development, energy reserves and $\alpha$-amylase activity of Plodia interpunctella Hübner (Lepidoptera: Pyralidae). J. Stored Prod. Res. 2008, 44, 290-294. [CrossRef]

29. Khosravi, R.; Sendi, J.J. Effect of neem pesticide (Achook) on midgut enzymatic activities and selected biochemical compounds in the hemolymph of lesser mulberry pyralid, Glyphodes pyloalis Walker (Lepidoptera: Pyralidae). J. Plant Prot. Res. 2013, 53, 238-247. [CrossRef]

30. Huang, Z.; Zhao, M.; Shi, P. Sublethal effects of azadirachtin on lipid metabolism and sex pheromone biosynthesis of the Asian corn borer Ostrinia furnacalis. Phytoparasitica 2012, 40, 361-368. [CrossRef]

31. Amirmohammadi, F.; Sendi, J.J.; Zibaee, A. Biomonitoring of the genotoxic and oxidative the effect of neemon mortality and physiological indices of Hyphantria cunea (Drury)(Lepidoptera). Munis. Entomol. Zool. 2012, 7, 489-495.

32. Dawkar, V.V.; Barage, S.H.; Barbole, R.S.; Fatangare, A.; Grimalt, S.; Haldar, S.; Heckel, D.G.; Gupta, V.S.; Thulasiram, H.V.; Svatoš, A. Azadirachtin-A from Azadirachta indica impacts multiple biological targets in cotton bollworm Helicoverpa armigera. ACS Omega 2019, 4, 9531-9541. [CrossRef] [PubMed]

33. Snart, C.J.; Hardy, I.C.; Barrett, D.A. Entometabolomics: Applications of modern analytical techniques to insect studies. Entomol. Exp. Appl. 2015, 155, 1-17. [CrossRef] [PubMed]

34. Klassen, A.; Faccio, A.T.; Canuto, G.A.B.; Da Cruz, P.L.R.; Ribeiro, H.C.; Tavares, M.F.M.; Sussulini, A. Metabolomics: Definitions and significance in systems biology. In Metabolomics: From Fundamentals to Clinical Applications; Springer: Berlin/Heidelberg, Germany, 2017; pp. 3-17.

35. Idle, J.R.; Gonzalez, F.J. Metabolomics. Cell Metab. 2007, 6, 348-351. [CrossRef] [PubMed]

36. Zhang, A.; Sun, H.; Wang, P.; Han, Y.; Wang, X. Modern analytical techniques in metabolomics analysis. Analyst 2012, 137, 293-300. [CrossRef]

37. Li, Y.; Wang, X.; Chen, Q.; Hou, Y.; Xia, Q.; Zhao, P. Metabolomics analysis of the larval head of the silkworm, Bombyx mori. Int. J. Mol. Sci. 2016, 17, 1460. [CrossRef]

38. Aliferis, K.A.; Jabaji, S. Metabolomics-A robust bioanalytical approach for the discovery of the modes-of-action of pesticides: A review. Pestic. Biochem. Phys. 2011, 100, 105-117. [CrossRef]

39. Lu, Y.; Zhang, Q.; Xu, W. Global metabolomic analyses of the hemolymph and brain during the initiation, maintenance, and termination of pupal diapause in the cotton bollworm, Helicoverpa armigera. PLoS ONE 2014, 9, e99948. [CrossRef] [PubMed]

40. Qu, L.J.; Wang, L.J.; Zhang, Y.A.; Wang, Q.H.; Wang, Y.Z.; Zhao, T.H.; Cai, W.Z. Radiation-Induced Metabolomic Changes in Sterile Male Monochamus alternatus (Coleoptera: Cerambycidae). J. Insect Sci. 2014, 14, 166. [CrossRef]

41. Killiny, N.; Hijaz, F.; El Shesheny, I.; Alfaress, S.; Jones, S.E.; Rogers, M.E. Metabolomic analyses of the haemolymph of the Asian citrus psyllid Diaphorina citri, the vector of huanglongbing. Physiol. Entomol. 2017, 42, 134-145. [CrossRef]

42. Liigand, P.; Heering, A.; Kaupmees, K.; Leito, I.; Girod, M.; Antoine, R.; Kruve, A. The evolution of electrospray generated droplets is not affected by ionization mode. J. Am. Soc. Mass Spectr. 2017, 28, 2124-2131. [CrossRef]

43. Mattila, J.; Hietakangas, V. Regulation of carbohydrate energy metabolism in Drosophila melanogaster. Genetics 2017, 207, 1231-1253.

44. Thompson, S.N.; Borchardt, D.B.; Wang, L. Dietary nutrient levels regulate protein and carbohydrate intake, gluconeogenic/glycolytic flux and blood trehalose level in the insect Manduca sexta L. J. Comp. Physiol. B 2003, 173, 149-163. [CrossRef] [PubMed]

45. Arrese, E.L.; Soulages, J.L. Insect fat body: Energy, metabolism, and regulation. Annu. Rev. Entomol. 2010, 55, 207-225. [CrossRef]

46. Sörensen, B. The Alpha-Linolenic Acid Requirements of Developing Heliothines. Ph.D. Thesis, Friedrich-Schiller-Universität, Jena, Germany, 17 June 2013. Available online: https://www.db-thueringen.de/receive/dbt_mods_00022437 (accessed on 15 June 2021).

47. Chang, C.L. Effect of amino acids on larvae and adults of Ceratitis capitata (Diptera: Tephritidae). Ann. Entomol. Soc. Am. 2004, 97, 529-535. [CrossRef]

48. Florkin, M. The free amino acids of insect haemolymph. In Biochemistry of Insects; Levenbook, L., Ed.; Pergamon Press: Oxford, UK, 1959; pp. 63-77.

49. Terra, W.C.; de Bianchi, A.G.; Gambarini, A.G.; Lara, F.J.S. Haemolymph amino acids and related compounds during cocoon production by larvae of the fly Rhynchosciara americana. J. Insect Physiol. 1973, 19, 2097-2106. [CrossRef]

50. Gammie, S.C.; Truman, J.W. Neuropeptide hierarchies and the activation of sequential motor behaviors in the hawkmoth Manduca sexta. J. Neurosci. 1997, 17, 4389-4397. [CrossRef] 
51. Scott, R.L.; Diao, F.; Silva, V.; Park, S.; Luan, H.; Ewer, J.; White, B.H. Non-canonical eclosion hormone-expressing cells regulate Drosophila ecdysis. iScience 2020, 23, 101108. [CrossRef] [PubMed]

52. Cerstiaens, A.; Huybrechts, J.; Kotanen, S.; Lebeau, I.; Meylaers, K.; De Loof, A.; Schoofs, L. Neurotoxic and neurobehavioral effects of kynurenines in adult insects. Biochem. Bioph. Res. Co. 2003, 312, 1171-1177. [CrossRef] [PubMed]

53. Navrotskaya, V.; Wnorowski, A.; Turski, W.; Oxenkrug, G. Effect of kynurenic acid on pupae viability of Drosophila melanogaster cinnabar and cardinal eye color mutants with altered tryptophan-kynurenine metabolism. Neurotox. Res. 2018, 34, 324-331. [CrossRef]

54. Teulier, L.; Weber, J.M.; Crevier, J.; Darveau, C.A. Proline as a fuel for insect flight: Enhancing carbohydrate oxidation in hymenopterans. Proc. R. Soc. B Biol. Sci. 2016, 283, 20160333. [CrossRef]

55. Newsholme, P.; Stenson, L.; Sulvucci, M.; Sumayao, R.; Krause, M. 1.02-Amino acid metabolism. In Comprehensive Biotechnology, 2nd ed.; Moo-Young, M., Ed.; Academic Press: Burlington, NJ, USA, 2011; pp. 3-14.

56. Chaudhary, S.; Kanwar, R.K.; Sehgal, A.; Cahill, D.M.; Barrow, C.J.; Sehgal, R.; Kanwar, J.R. Progress on Azadirachta indica based biopesticides in replacing synthetic toxic pesticides. Front. Plant Sci. 2017, 8, 610. [CrossRef] [PubMed]

57. Worley, B.; Powers, R. Multivariate analysis in metabolomics. Curr. Metabolomics 2013, 1, 92-107. [PubMed]

58. Westerhuis, J.A.; Hoefsloot, H.C.; Smit, S.; Vis, D.J.; Smilde, A.K.; van Velzen, E.J.; van Duijnhoven, J.P.; van Dorsten, F.A. Assessment of PLSDA cross validation. Metabolomics 2008, 4, 81-89. [CrossRef]

59. Saccenti, E.; Hoefsloot, H.C.; Smilde, A.K.; Westerhuis, J.A.; Hendriks, M.M. Reflections on univariate and multivariate analysis of metabolomics data. Metabolomics 2014, 10, 361-374. [CrossRef]

60. Kanehisa, M.; Araki, M.; Goto, S.; Hattori, M.; Hirakawa, M.; Itoh, M.; Katayama, T.; Kawashima, S.; Okuda, S.; Tokimatsu, T. KEGG for linking genomes to life and the environment. Nucleic. Acids Res. 2008, 36, 480-484. [CrossRef] 